\title{
MACHADO DE ASSIS E A DIVINA COMÉDIA
}

\section{TERESINHA VÂNIA ZIMBRÃO DA SILVA}

Universidade Federal de Juiz de Fora

Juiz de Fora, Minas Gerais, Brasil

\section{IZABELLA MADDALENO}

Universidade Federal de Juiz de Fora

Juiz de Fora, Minas Gerais, Brasil

Resumo: A proposta deste artigo é estudar as referências à Divina comédia presentes na obra do escritor brasileiro Machado de Assis. Para tanto, dialogaremos com os estudos de alguns pesquisadores, tais como: Edoardo Bizarri, Jean-Michel Massa, Eugenio Vinci de Moraes, dentre outros.

Palavras-chave: Machado de Assis; Divina Comédia; referências.

\section{MACHADO DE ASSIS AND THE DIVINE COMEDY}

Abstract: This article puts forth the study of references to The Divine Comedy in the work of Brazilian writer Machado de Assis. Therefore, our discussion will dialogue the work of researchers such as Edoardo Bizarri, Jean-Michel Massa, Eugenio Vinci de Moraes.

Keywords: Machado de Assis; The Divine Comedy; references. 
Dante foi entre os autores preferidos por Machado de Assis, que dele fez objeto de estudo e de culto durante toda a sua vida. Esta predileção não pode causar estranheza se considerarmos as exigências estilístico-estéticas de Machado e seu intimo conjugar-se com uma severa estrutura moral; é de estranhar, ao contrário, não tê-la os estudiosos devidamente sublinhada e analisada, pois basta denunciá-la a frequência de citações dantescas, em italiano, na obra de Machado, durante mais de quarenta anos.

Edoardo Bizarri, Machado de Assis e a Itália

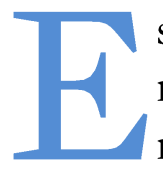

ste trabalho se propõe a contribuir para o estudo das referências machadianas à obra de Dante Alighieri, A divina comédia, revisitando os poucos críticos que se ocuparam do tema e acrescentando algumas considerações que esperamos serem relevantes para esses estudos.

É bem notável que o autor brasileiro fez referências a culturas e literaturas diversas, de tal forma que alguns críticos debruçaram-se sobre a sua obra a fim de investigar tais particularidades. Os trabalhos mais conhecidos vão desde o do crítico Eugênio Gomes (1939), que analisou as influências inglesas em Machado, ao de Gilberto Pinheiro Passos (1996), que estudou a presença francesa no romance machadiano.

No entanto, a referência italiana em Machado, dada a sua significativa recorrência, merece mais estudos por parte da crítica. Com efeito, a relação existente entre Machado de Assis e a Itália foi um tema que quase passou despercebido pela fortuna crítica do escritor. Contudo, alguns pesquisadores dele se ocuparam, sobretudo no que diz respeito a Dante Alighieri, como veremos em seguida.

\section{Edoardo Bizarri}

O primeiro estudo de peso sobre a referência italiana na obra de Machado foi feito por Edoardo Bizarri, que dissertou sobre o assunto em Machado de Assis e a Itália (1961), e também no artigo "Machado de Assis e 
Dante" (1965). No seu estudo, o italiano fez um exaustivo levantamento das citações diretas de versos dantescos que comparecem na obra do escritor brasileiro, como veremos adiante.

Não se sabe ao certo, devido à falta de documentação de cunho biográfico, quando Machado teve os seus primeiros contatos com a língua italiana. O que se sabe é que os escritos machadianos sobre a Itália são perceptíveis desde a sua juventude, principalmente nos gêneros poesia e crônica, nos quais já era notável o uso de palavras e expressões italianas, bem como assevera Bizarri:

De qualquer forma, certo e incontestável é que o interesse pela língua, a arte e as coisas da Itália aparece muito cedo em Machado. A uma italiana (que obviamente é cantora) foi dedicada uma das primeiras poesias de Machado, que então contava dezesseis anos: esta poesia leva a data de 29 de julho de 1855, tendo sido publicada na Marmota fluminense de 15 de julho daquele mesmo ano. (BIZARRI, 1961, p. 7)

Vale reiterar que Machado era um apreciador das óperas italianas, citando-as inúmeras vezes. Assim, notamos o quanto ele estava envolvido com a língua e a cultura da Itália, demonstrando ainda ser um grande leitor e conhecedor da literatura italiana, tendo o hábito de citar versos dos autores italianos em língua original, dentre os quais, além de Leopardi e Tasso, "menciona ocasionalmente Giosué Carducci, Cesare Cantú, Cesare Lombroso e Paolo Mantegazza" (BIZARRI, 1961, p. 22-23). Entretanto, o encanto maior de Machado foi por Dante Alighieri. Cabe comentar que na biblioteca de Machado de Assis consta um exemplar em italiano de La divina commedia, publicado em 1868, como podemos constatar nas pesquisas feitas por Jean-Michel Massa (1961), "La bibliothèque de Machado de Assis" e José Luís Jobim (2001), A biblioteca de Machado de Assis.

Deveras, as referências dantescas podem ser vistas em toda a obra machadiana, sejam elas com citações diretas de versos ou não. O apreço pelo escritor florentino é tão significativo que o autor brasileiro não deixou de expressar a sua admiração pela grandiosidade de Dante, dedicando-lhe expressões elogiosas, tal como destacado por Bizarri:

Com ou sem citações dos versos originais, numerosas são na obra de Machado cronista e narrador as referências a Dante e ao seu poema: ao "meu Dante", ao "divino Dante", aos "versos divinos do poeta", que na lírica "1802-1885", escrita em ocasião da morte de Victor Hugo, é 
representado como "... o velho e grave florentino/ que mergulha no abismo, e caminha no assombro/ baixa humano ao inferno e regressa divino". (BIZARRI, 1961, p. 19)

Cabe acrescentar que a forma métrica dos tercetos, a mesma adotada n'A divina comédia, era utilizada por Machado, embora não fosse tão comum na escrita dos poetas brasileiros. ${ }^{1}$ Pondera Bizarri que este seria um indício de que o autor era de fato um hábil estudioso da obra literária do florentino:

Outro indício significativo do estudo do poema de Dante é fornecido pelo interesse que Machado poeta dispensa ao terceto e pela segurança com a qual domina esta forma métrica "muito pouco usada na poesia portuguesa, tanto tradicional, como do tempo", conforme afirma Mário de Andrade. (BIZARRI, 1961, p. 21)

E aqui importa notar que, antes de Bizarri, Mário de Andrade já havia relacionado Machado de Assis e Dante Alighieri. De fato, ao lermos o seu ensaio sobre Machado de Assis, em Aspectos da literatura brasileira (1974 [1939]), citado por Bizarri a respeito dos tercetos, confirmamos que o modernista analisou então o poema machadiano "Última jornada", de 1875, como sendo de inspiração dantesca. Eis suas palavras no mencionado ensaio a respeito de Machado: "quem o teria inspirado? [...] A mim tenho como certo que foi Dante, no episódio de Paolo e Francesca" (ANDRADE, 1974, p. 100). E para comprovar sua afirmação, além de invocar o uso machadiano dos tercetos e de semelhanças com Dante na ideação do poema, acrescenta ainda o que ele chama de possíveis "reminiscências" dantescas em "Última jornada", que contariam como referências indiretas a Dante.

Bizarri não comenta a análise de Mário de Andrade, somente a sua afirmação sobre o uso machadiano dos tercetos, talvez por não haver no poema nenhuma citação explícita ao escritor florentino e aos seus versos. A preocupação maior do estudioso italiano é o levantamento das citações diretas de versos de Dante na obra do escritor brasileiro.

Machado ainda traduziu o canto XXV do Inferno, um dos menos estudados e comentados pela crítica da época. Sua tradução dos versos dantescos foi descrita por Bizarri como uma das melhores já realizadas até

\footnotetext{
${ }^{1}$ É verdade que Gonçalves de Magalhães e Gonçalves Dias utilizaram os tercetos antes de Machado e também deles se utilizou o parnasiano Olavo Bilac, como bem lembrado pela Profa. Dra. Maria Andréia Paula, a quem agradecemos a observação.
} 
então para o português, sendo respeitada a estrutura linguística, o ritmo e o estilo de Dante:

Enfim, temos a tradução que Machado fez do canto XXV do Inferno, publicando-o inicialmente no "Globo" de 25 de dezembro de 1874. É, fora de dúvidas, a melhor tradução que Dante teve em língua portuguesa: não apenas pelo respeito à forma métrica original, mas também por conservar ao máximo, compativelmente com a diferente estrutura linguística, o ritmo e o estilo de Dante. (BIZARRI, 1961, p. 21)

É verdade que outras traduções d'A divina comédia foram publicadas desde que Bizarri escreveu o seu artigo em 1961, mas o mérito de Machado como tradutor de Dante persiste e é atestado por estudos recentes sobre as traduções de Machado de Assis. ${ }^{2}$

Enfim, como mencionamos, Bizarri levantou quantitativamente as citações diretas que o autor brasileiro realizou dos versos dantescos. Importa notar que o estudioso italiano não se preocupou com interpretações, e sim em fazer um levantamento. As obras citadas por Machado foram Vita nuova e A divina comédia:

A primeira citação de Dante, extraída do capítulo XXIII da Vita Nuova, remonta, como já vimos, ao ano de 1864; as últimas encontram-se no Memorial de Aires, publicado em 1908, dois meses antes do falecimento do escritor.

Em conjunto, na obra de ficção de Machado encontramos onze citações de Dante, e precisamente em: "Versos a Corina" (1864), epígrafe; "Aurora sem dia" (1873); A mão e a luva (1874), cap. 6; Helena (1876), cap. 21; "O alienista" (1881); Dom Casmurro (1899), cap. 129; Esaú e Jacó (1904), frontispício e cap. 12; Memorial de Aires (1908), sob as datas de 11 de fevereiro e 12 de setembro de 1888. A não ser a citação da Vita Nuova, as outras provêm do I, III (duas), V (três) e XXXIII canto do Inferno, e do V, XII e XXXIII canto do Purgatório, revelando portanto um conhecimento bastante amplo das duas primeiras partes da Divina comédia. Mais doze citações dantescas que podem ser encontradas na obra de Machado jornalista, e provêm dos cantos III (quatro), V (cinco), XX e XXV do Inferno e do XXXIII do Purgatório. (BIZARRI, 1961, p. 1819)

${ }^{2}$ Ver, sobretudo, Flores (2017). 
Note-se que o levantamento de Bizarri pontua somente as referências dantescas com citações de versos, e, veremos adiante, quando falarmos sobre os estudos de outros críticos, que uma citação direta de verso dantesco lhe escapou. Sobre as citações em jornais levantadas por Bizarri, importa acrescentar a nota de rodapé do estudioso italiano revelando onde elas poderiam ser encontradas:

Vejam-se o ensaio A nova geração (1879) e as crônicas de 1 de dezembro de 1877 na Ilustração Brasileira; de 16 de junho de 1878 no Cruzeiro; de 12 de novembro de 1886, 13 de janeiro de 1889, 23 de agosto de 1893, 9 de junho de 1895, 26 de janeiro, 5 de julho e 1 de novembro de 1896 na Gazeta de Notícias. (BIZARRI, 1961, p. 19)

Este foi o levantamento feito por Bizarri no estudo de 1961, totalizando 23 citações, onze na obra literária e doze na jornalística. Em 1965, ele retoma esse levantamento, que abarca desde a primeira citação em 1864 à última em 1908, mas Bizarri (1965, p. 133) faz então a seguinte afirmação: "No arco da produção machadiana nesses quarenta e quatro anos encontramos 24 citações dantescas (sem contar as referências diretas ou indiretas ao Poeta); das quais onze na obra de ficção e treze na produção jornalística". Bizarri totaliza agora 24 citações em vez de 23, pois aumentou de doze para treze as citações na obra jornalística. Note-se que, em alguns casos, o estudioso conta duas citações por crônica, de onde, talvez, a imprecisão na contagem delas em 1961.

Ainda a respeito dessas citações em jornal, notamos, no nosso levantamento, a ser detalhado nos quadros adiante, algumas imprecisões em relação às datas: a crônica de $1^{\circ}$ de dezembro de 1877 na Ilustração Brasileira, que compõe a coletânea publicada entre 1876 e 1878 sob o título "História de 15 dias", não apresenta citação dantesca, esta foi encontrada na crônica de $1^{0}$ de janeiro de 1877 da mesma coletânea; a crônica de 12 de novembro de 1886, da coletânea publicada entre 1886 e 1888 na Gazeta de Notícias sob o título "Gazeta de Holanda", também não apresenta citação dantesca, sendo esta encontrada na crônica de 13 de maio de 1887 da mesma coletânea; a crônica de 23 de agosto de 1893, que compõe a coletânea "A semana", publicada entre 1892 e 1897 na Gazeta de Notícias, também não apresenta a citação dantesca, esta foi encontrada na crônica do dia 27 de agosto de 1893 da mesma coletânea. 
Para uma melhor visualização, organizamos os quadros que se seguem: os dois primeiros com as onze citações dantescas na obra literária de Machado e o terceiro, com as treze citações na obra jornalística.

\begin{tabular}{|c|c|c|}
\hline Obra & Citação de Machado & $\begin{array}{l}\text { Versos d'A divina comédia } \\
\text { (ALIGHIERI, 2010) }\end{array}$ \\
\hline $\begin{array}{l}\text { "Aurora sem dia" } \\
\text { In: Histórias da } \\
\text { meia-noite } \\
(1873)\end{array}$ & $\begin{array}{l}\text { Esta obra tinha por epígrafe o } \\
\text { nessun maggior dolore do poeta } \\
\text { florentino. } \\
\text { (ASSIS, 2015b, p. 205) }\end{array}$ & $\begin{array}{l}\text { [...] Nessun maggior dolore. } \\
\text { (ALIGHIERI, 2010, Inf. 5, } \\
\text { 121) }\end{array}$ \\
\hline $\begin{array}{l}\text { A mão e a luva } \\
\text { (1874) } \\
\text { Cap. } 6\end{array}$ & $\begin{array}{l}\text { Sobre tudo isto o obstáculo, aquela } \\
\text { porta fechada, que bem podia ser a } \\
\text { da città dolente, mas que em todo o } \\
\text { caso ele quisera ver franqueada às } \\
\text { suas ambições. } \\
\text { (ASSIS, 2015a, p. 329) }\end{array}$ & $\begin{array}{l}\text { Per me si va ne città dolente. } \\
\text { (ALIGHIERI, 2010, Inf. } 3,1 \text { ) }\end{array}$ \\
\hline $\begin{array}{l}\text { Helena } \\
(1876) \\
\text { Cap. } 21\end{array}$ & $\begin{array}{l}\text { Semelhante ao transviado } \\
\text { florentino, achava-se no meio de } \\
\text { uma selva escura, a igual distância } \\
\text { da estrada reta, - diritta via - e da } \\
\text { fatal porta, onde temia ser } \\
\text { despojado de todas as esperanças. } \\
\text { (ASSIS, 2015a, p. 458) }\end{array}$ & $\begin{array}{l}\text { Nel mezzo del cammin di } \\
\text { nostra vita } \\
\text { mi ritrovai per una selva } \\
\text { oscura } \\
\text { ché la diritta via era } \\
\text { smarrita. } \\
\text { (ALIGHIERI, 2010, Inf. 1, 1- } \\
\text { 3) }\end{array}$ \\
\hline $\begin{array}{l}\text { Memórias póstumas } \\
\text { de Brás Cubas } \\
\text { (1881) } \\
\text { Cap. } 57\end{array}$ & $\begin{array}{l}\text { Achávamo-nos jungidos um ao } \\
\text { outro, como as duas almas que o } \\
\text { poeta encontrou no Purgatório: } \\
\text { Di pari, come buoi, che vanno a } \\
\quad \text { giogo; } \\
\text { (ASSIS, 2015a, p. } 657 \text { ) }\end{array}$ & $\begin{array}{l}\text { Di pari, come buoi che } \\
\text { vanno a giogo. } \\
\text { (ALIGHIERI, 2010, Purg. 12, } \\
\text { 1) }\end{array}$ \\
\hline $\begin{array}{l}\text { "O alienista" } \\
\text { In: Papéis avulsos } \\
\text { (1882) } \\
\text { Cap. } 5\end{array}$ & $\begin{array}{l}\text { O padre Lopes, que cultivava o } \\
\text { Dante, e era inimigo do Coelho, } \\
\text { nunca o via desligar-se de uma } \\
\text { pessoa que não declamasse e } \\
\text { emendasse este trecho: } \\
\text { La bocca sollevò dal fiero pasto } \\
\text { Quel "seccatore" [...] } \\
\text { (ASSIS, 2015b, p. 244) }\end{array}$ & $\begin{array}{l}\text { La bocca sollevò dal fiero } \\
\text { pasto } \\
\text { quel peccator... } \\
\text { (ALIGHIERI, 2010, Inf. 33, } \\
\text { 1-2) }\end{array}$ \\
\hline
\end{tabular}




\begin{tabular}{|c|c|c|}
\hline $\begin{array}{l}\text { Dom Casmurro } \\
\text { (1899) } \\
\text { Cap. } 129\end{array}$ & $\begin{array}{l}\text { Um dia, iremos daqui até à porta } \\
\text { do céu, onde nos encontraremos } \\
\text { renovados, como as plantas novas, } \\
\text { come piante novelle, } \\
\quad \text { Rinovellate di novelle fronde. } \\
\text { O resto em Dante. } \\
\text { (ASSIS, 2015a, p. 1029) }\end{array}$ & $\begin{array}{l}\text { rifatto sí come piante } \\
\text { novelle } \\
\text { rinovellate di novella fronda. } \\
\text { (ALIGHIERI, 2010, Purg. } \\
\text { 33, 143-144) }\end{array}$ \\
\hline $\begin{array}{l}\text { Esaú e Jacó } \\
\text { (1904) } \\
\text { Epígrafe } \\
\text { Cap. } 22\end{array}$ & $\begin{array}{l}\text { Dico, che quando l'anima mal nata... } \\
\text { (ASSIS, 2015a, p. 1046). } \\
\text { Eu posso, truncando um verso ao } \\
\text { meu Dante, escrever de tais } \\
\text { insípidos: } \\
\text { Dico, che quando l'anima mal nata... } \\
\text { (ASSIS, 2015a, p. 1065) }\end{array}$ & $\begin{array}{l}\text { Dico che quando l'anima } \\
\text { mal nata. } \\
\text { (ALIGHIERI, 2010, Inf. 5, 7) }\end{array}$ \\
\hline $\begin{array}{l}\text { Memorial de Aires } \\
\text { (1908) } \\
11 \text { de fevereiro de } \\
1888\end{array}$ & $\begin{array}{l}\text { Verdade é que o nome da família, } \\
\text { que serve ao título nobiliário, } \\
\text { Santa-Pia, também não o acho na } \\
\text { lista dos canonizados, e a única } \\
\text { pessoa que conheço, assim } \\
\text { chamada, é a de Dante: Ricorditi di } \\
\text { me, chi son la Pia. } \\
\text { (ASSIS, 2015a, p. 1212) } \\
\text { Entrei nesta dúvida, - se teriam } \\
\text { estado juntos na rua ou na loja a } \\
\text { que ela veio, ou no banco, ou no } \\
\text { inferno, que também é lugar de } \\
\text { namorados, é certo que de } \\
\text { namorados viciosos, del mal } \\
\text { perverso. } \\
\text { (ASSIS, 2015a, p. 1246) }\end{array}$ & $\begin{array}{l}\text { ricorditi di me, che son la } \\
\text { Pia. } \\
\text { (ALIGHIERI, 2010, Purg. 5, } \\
\text { 133) }\end{array}$ \\
\hline
\end{tabular}

E ainda a citação machadiana, no poema "Versos a Corina", da única obra de Dante que não é $A$ divina comédia.

\begin{tabular}{|l|l|l|}
\hline Obra & Citação de Machado & Vita Nuova cap. XXIII \\
\hline $\begin{array}{l}\text { Poesia: "Versos a } \\
\text { Corina" }\end{array}$ & $\begin{array}{l}\text { Tacendo il nome di questa } \\
\text { gentilíssima. }\end{array}$ & $\begin{array}{l}{[. . .] \text { tacendo lo nome di questa }} \\
\text { gentilissima. }\end{array}$ \\
\hline
\end{tabular}


Machado de Assis em Linha — Universidade de São Paulo

http://machadodeassis.fflch.usp.br

\begin{tabular}{|l|l|l|}
\hline In: Crisálidas & (ASSIS, 2015c, p. 397) & (ALIGHIERI, 1932, p. 36) \\
(1864) & & \\
Epígrafe & & \\
\hline
\end{tabular}

Por fim, as treze citações dantescas na obra jornalística. Como mencionamos, em alguns casos contam-se duas citações por crônica.

\begin{tabular}{|c|c|c|}
\hline Obr & Citação machadiana & Versos d'A Divina Comédia \\
\hline $\begin{array}{l}\text { "História de } 15 \text { dias" } \\
\text { In: Ilustração Brasileira }\end{array}$ & $\begin{array}{l}\text {...qui mi scusi } \\
\text { A urgência, si fior la penna } \\
\text { abborra. } \\
\text { (ASSIS, 2015d, p. 314) }\end{array}$ & $\begin{array}{l}\text { [...] e qui mi scusi } \\
\text { la novità se fior la penna } \\
\text { abborra. } \\
\text { (ALIGHIERI, 2010, Inf. 25, } \\
\text { 143-144) }\end{array}$ \\
\hline $\begin{array}{l}16 \text { de junho de } 1878 \\
\text { "Notas semanais" } \\
\text { In: O Cruzeiro }\end{array}$ & $\begin{array}{l}\text {... che'l pianto degliocchi } \\
\text { Le natiche bagnava per lo } \\
\text { ferro. } \\
\text { (ASSIS, 2015d, p. 388) }\end{array}$ & $\begin{array}{l}\text { [...] che'l pianto de li occhi } \\
\text { le natiche bagnava per lo } \\
\text { fesso. } \\
\text { (ALIGHIERI, 2010, Inf. 20, } \\
23-24 \text { ) }\end{array}$ \\
\hline $\begin{array}{l}1^{\circ} \text { de dezembro de } 187 \\
\text { "A nova geração" } \\
\text { In: Revista Brasileira }\end{array}$ & $\begin{array}{l}\text { ar de lor, ma } \\
\text { sa. } \\
\text { c, p. 1248) }\end{array}$ & $\begin{array}{l}\text { non ragioniam di lor, ma } \\
\text { guarda e passa. } \\
\text { (ALIGHIERI, 2010, Inf. } 3,51 \text { ) }\end{array}$ \\
\hline $\begin{array}{l}\text { "Gaze } \\
\text { In: } G c\end{array}$ & $\begin{array}{l}\text { mo os de que fala o Dante, } \\
\text { San cantando lor lai; } \\
\text { SSIS, 2015d, p. 668) }\end{array}$ & $\begin{array}{l}\text { E come i gru van cantando lor } \\
\text { lai, } \\
\text { (ALIGHIERI, 2010, Inf. } 5,46 \text { ) }\end{array}$ \\
\hline $\begin{array}{l}13 \text { de janeiro de } 1889 \\
\text { "Bons dias!" } \\
\text { In: Gazeta de Notícias }\end{array}$ & $\begin{array}{l}\text { ogni speranza, o voi } \\
\text { te! } \\
\text { 2015d, p. 792) }\end{array}$ & $\begin{array}{l}\text { Lasciate ogne speranza, voi } \\
\text { ch'entrate. } \\
\text { (ALIGHIERI, 2010, Inf. } 3,9 \text { ) }\end{array}$ \\
\hline $\begin{array}{l}27 \text { de agosto de } 1893 \\
\text { "A semana" } \\
\text { In: Gazeta de Notícias }\end{array}$ & $\begin{array}{l}\text { E come i gru van cantando lor } \\
\text { lai, } \\
\text { Facendo in aere di sè lunga } \\
\text { riga, } \\
\text { (ASSIS, } 2015 \mathrm{~d}, \mathrm{p} .944 \text { ) } \\
\text { E como i gru van cantando lor } \\
\text { lai }\end{array}$ & $\begin{array}{l}\text { E come i gru van cantando lor } \\
\text { lai, faccendo in aere di sé } \\
\text { lunga riga. } \\
\text { (ALIGHIERI, 2010, Inf. 5, 46- } \\
\text { 47) } \\
\text { E come i gru van cantando lor } \\
\text { lai, }\end{array}$ \\
\hline
\end{tabular}


Machado de Assis em Linha - Universidade de São Paulo

http://machadodeassis.fflch.usp.br

\begin{tabular}{|c|c|c|}
\hline & (ASSIS, 2015d, p. 944) & (ALIGHIERI, 2010, Inf. 5, 46) \\
\hline $\begin{array}{l}9 \text { de junho de } 1895 \\
\text { "A semana" } \\
\text { In: Gazeta de Notícias }\end{array}$ & $\begin{array}{l}\text { Fama di loro il mondo esser } \\
\text { non lassa; } \\
\text { Misericórdia e giustizia li } \\
\text { sdegna: } \\
\text { Non ragioniam di lor, ma } \\
\text { guarda e passa. } \\
\text { (ASSIS, 2015d, p. 1101) }\end{array}$ & $\begin{array}{l}\text { Fama di loro il mondo esser } \\
\text { non lassa; } \\
\text { misericordia e giustiza li } \\
\text { sdegna: } \\
\text { non ragioniam di lor, ma } \\
\text { guarda e passa. } \\
\text { (ALIGHIERI, 2010, Inf. 3, 49- } \\
\text { 51) }\end{array}$ \\
\hline $\begin{array}{l}26 \text { de janeiro de } 1896 \\
\text { "A semana" } \\
\text { In: Gazeta de Notícias }\end{array}$ & $\begin{array}{l}\text { Lasciate ogni speranza, voi } \\
\text { ch'entrate; } \\
\text { (ASSIS, 2015d, p. 1164) } \\
\text { Venite a noi parlar, s'altri nol } \\
\text { niega. } \\
\text { (ASSIS, 2015d, p. 1164) }\end{array}$ & $\begin{array}{l}\text { Lasciate ogni speranza, voi } \\
\text { ch'entrate. } \\
\text { (ALIGHIERI, 2010, Inf. 3, 9) } \\
\text { venite a noi parlar, s'altri nol } \\
\text { niega! } \\
\text { (ALIGHIERI, 2010, Inf. } 5,81 \text { ) }\end{array}$ \\
\hline $\begin{array}{l}5 \text { de julho de } 1896 \\
\text { "A semana" } \\
\text { In: Gazeta de Notícias }\end{array}$ & $\begin{array}{l}\text { Rifatto si, come piante novelle } \\
\text { Rinnovellate di novella } \\
\text { fronda... } \\
\text { (ASSIS, 2015d, p. 1209) }\end{array}$ & $\begin{array}{l}\text { rifatto sì come piante novelle } \\
\text { rinovellate di novella fronda, } \\
\text { (ALIGHIERI, 2010, Purg. 33, } \\
\text { 143-144) }\end{array}$ \\
\hline $\begin{array}{l}\text { 1 de novembro de } 1896 \\
\text { "A semana" } \\
\text { In: Gazeta de Notícias } \\
\text { (duas citações) }\end{array}$ & $\begin{array}{l}\text { [...] não só o dos dolci sospiri, } \\
\text { como o da sua rima dubbiosi } \\
\text { desiri. Não caberia aqui contar } \\
\text { como Francesca: } \\
\text { Questi che mai da me non fia } \\
\quad \text { diviso, } \\
\text { (ASSIS, 2015d, p. 1244) }\end{array}$ & $\begin{array}{l}\text { [...] Al tempo d'i dolci sospiri, } \\
\text { [...] che conosceste i dubbiosi } \\
\text { disiri? } \\
\text { (ALIGHIERI, 2010, Inf. 5, 118- } \\
\text { 120) } \\
\text { questi, que mai da me non fia } \\
\text { diviso. } \\
\text { (ALIGHIERI, 2010, Inf. 5, } \\
\text { 135) }\end{array}$ \\
\hline
\end{tabular}

Eis então o levantamento feito por Bizarri das citações de versos dantescos na obra de Machado. O estudioso ainda pontuou, sem preocupação de fazer um levantamento, algumas referências diretas a Dante ou à Divina comédia, sem citação de versos, que não estamos considerando neste trabalho.

Depois do italiano, coube ao francês Jean-Michel Massa o papel de pesquisar a presença de Dante em Machado de Assis. 


\section{Jean-Michel Massa}

Notemos que Massa não fez acréscimos às citações inventariadas por Bizarri. No seu estudo, escrito em 1965, "A presença de Dante na obra de Machado de Assis" (MASSA, 2015), além de comentar algumas citações de Dante já levantadas por Bizarri, também comentou a tradução do Canto 25 do Inferno, a qual dedicaria mais atenção no estudo de 1970, Machado de Assis tradutor (MASSA, 2008). Escreveu ele então sobre o domínio machadiano da língua italiana:

Machado de Assis cita com frequência a Divina Comédia em suas obras. Quando se coloca Dante no texto, tem-se um conhecimento profundo do italiano. A versão que ele propõe do canto XXV por sua fidelidade, e suas infidelidades, testemunha suficientemente sua mestria nessa língua romana. (MASSA, 2008, p. 49)

Massa tentou entender o motivo que levou o escritor brasileiro a escolher o Canto 25, sugerindo a hipótese das pesquisas formais, tão em moda no Parnasianismo, e comentou sobre a versão de Machado:

Machado de Assis admirava Dante profundamente, e notamos que a escolha do Canto XXV do Inferno, que constitui uma homenagem ao poeta italiano, teria talvez um significado mais dinâmico, que integrasse Dante às diversas pesquisas formais efetuadas pela escola parnasiana. De sorte que a Divina Comédia, relida em 1874, parecia próxima, por seus motivos plásticos e escultóricos, da estética do tempo. (MASSA, 2008, p. 85)

Massa ainda destacou a qualidade da tradução de Machado e o seu domínio da terza rima:

O valor da tradução feita por Machado de Assis deriva de sua grande fidelidade ao texto original, e a versão brasileira é fiel à letra e ao espírito das terzine dantescas. Machado de Assis, numa linguagem firme e vigorosa, ultrapassou os obstáculos técnicos, mesmo os da terza rima cujo emprego é tão delicado. (MASSA, 2008, p. 85)

Após esses olhares lançados na década de 1960 e 1970 pelos críticos italiano e francês acerca da presença de Dante Alighieri na obra machadiana, destacamos em seguida um outro estudioso que, quatro décadas depois, se 
ocupou das referências feitas por Machado de Assis à obra dantesca $A$ divina comédia.

\section{Eugenio Vinci de Moraes}

O pesquisador Eugenio Vinci de Moraes (2007), em sua tese de doutoramento intitulada $A$ Tijuca e o pântano. A Divina Comédia na obra de Machado de Assis entre 1870 e 1881, defendida na Universidade de São Paulo, retomou o trabalho de Edoardo Bizarri, encontrando e acrescentando uma citação direta de verso de Dante presente no poema machadiano "Niâni", que escapou ao levantamento feito pelo italiano em 1961-1965, acréscimo que organizamos no quadro a seguir:

\begin{tabular}{|l|l|l|}
\hline Obra & Citação de Machado & Versos d'A Divina Comédia \\
\hline "Niâni" & ...che piange & {$[\ldots .$.$] che piagne$} \\
In: Americanas & Vedova, sola. & vedova e sola [...] \\
(1875) & (ASSIS, 2015c, p. 497) & (ALIGHIERI, 2010, Purg. 6, 112-113) \\
Epígrafe & & \\
\hline
\end{tabular}

De fato, com o achado de Moraes, o número de citações diretas de versos dantescos na obra machadiana subiu em uma citação, totalizando 25 citações. Ao contrário de Bizarri, cuja preocupação maior foi levantar as citações, Moraes se dedicou à interpretação delas, mais precisamente daquelas que comparecem nos romances Helena (verso do canto 1 do Inferno), Memórias póstumas de Brás Cubas (verso do canto 12 do Purgatório) e no conto "O alienista" (verso do canto 33 do Inferno).

Notemos que, ao interpretar a citação dantesca em Memórias póstumas de Brás Cubas, Moraes mencionou uma interpretação anterior, "Uma página dantesca de Machado de Assis", artigo de Oswaldo Ceschin (1999) que lhe teria servido de inspiração e que se soma à fortuna crítica dos estudos sobre Dante e Machado. Moraes interpretou ainda algumas referências a Dante e à Divina comédia, sem citação de versos, apontadas por Bizarri, além de interpretar o poema "Última jornada" como sendo de fato inspirado no canto 5 do Inferno, tal como defendeu primeiro Mário de Andrade.

Saindo do espaço definido pelo levantamento de Bizarri, Moraes interpretou a citação de verso dantesco que ele próprio descobriu no poema "Niâni", além de defender a autoria machadiana de uma paródia a Dante e a 
interpretar. De fato, em Vida e obra de Machado de Assis, Raimundo Magalhães Júnior (1981) comenta sobre uma possível paródia de Machado ao Inferno de Dante, sob o pseudônimo Dr. Semana, publicada em crônica de 12 de julho de 1874 da Semana Ilustrada sob o título "Inferno - canto suplementar ao poema de Dante pelo Dr. Semana", composta por 109 versos. Foi essa paródia que Moraes defendeu e interpretou como sendo machadiana.

Enfim, se Moraes interpretou as citações de versos dantescos levantadas por Bizarri nos romances machadianos Helena, Memórias póstumas de Brás Cubas e no conto "O alienista", nos propomos aqui a contribuir para a interpretação da citação do verso de Dante que o estudioso italiano levantou no penúltimo romance de Machado de Assis, publicado em 1904, Esaú e Jacó.

Dico, che quando l'anima mal nata...

Pouco antes do levantamento de 1961 feito por Bizarri, o crítico machadiano Eugênio Gomes, em 1958, escreveu o ensaio "O testamento estético de Machado de Assis", onde estudou o romance Esaú e Jacó e interpretou a citação de Dante, Dico, che quando l'anima mal nata... A citação comparece duas vezes no romance, como epígrafe e também no capítulo 12 , quando o conselheiro e diplomata Aires, ao escrever o seu Memorial, utiliza o verso para adjetivar a gente desinteressante e insípida que encontrara numa reunião social. Na interpretação de Gomes, o verso se refere às personagens de Esaú e Jacó vítimas da Paixão e, portanto, escravas da Vontade, se assemelhando aos indivíduos vulgares que Schopenhauer descrevera na sua filosofia dos Aforismos, livro que Machado tinha em sua biblioteca tanto na tradução francesa de 1880 como na edição alemã de 1886, como comprovam os estudos feitos por Massa e Jobim sobre a sua biblioteca, já mencionados neste artigo. $\mathrm{O}$ verso é tirado ao Canto 5 do segundo círculo do Inferno de Dante. Lá estava o juiz Minos a receber e julgar todas as almas infernais. Quando chegava uma anima mal nata, predestinada desde o nascimento à total desventura, era Minos quem lhe indicava o exato círculo onde iria penar o eterno castigo. De onde Gomes conclui:

Entre as personagens de Esaú e Jacó quem havia de escapar à condenação daquele Cérbero? Batista, o político intolerante e desonesto? D. Cláudia, uma ambiciosa vulgar, saudosa do poder, insensível às catilinárias da oposição, desde que o marido não perdesse 
o cargo? Santos, homem cordato, mas perdidamente escravizado às seduções do dinheiro? Natividade, a mulher, com a ideia fixa da grandeza dos filhos incrustada na imaginação? Os gêmeos Pedro e Paulo, que traziam do berço o estigma do ódio e da discórdia, cada qual mais atiçado pela ambição de subir e ter o mundo debaixo de seus pés? Nóbrega, o antigo irmão das almas, que a fortuna converteu em "grande homem", sem ter deixado jamais de ser um refinado patife? (GOMES, 2015, p. 97)

$\mathrm{Na}$ verdade, esta interpretação filosófica do romance foi um lugar comum na crítica machadiana das décadas de 1960 e 1970. De fato, José Guilherme Merquior (1977), em "Machado de Assis e a prosa impressionista", reafirmaria que os personagens de Esaú e Jacó se assemelhavam aos indivíduos vulgares que Schopenhauer descrevera na sua filosofia como sucumbindo à Paixão e à Vontade.

Décadas depois, em "Machado de Assis: Dico, che quando l'anima mal nata", Teresinha Zimbrão da Silva (2015) rearticulou esta leitura, dando-lhe um viés sociológico: as personagens vulgares seriam na verdade almas "malnascidas" em berço pobre que, embora tendo ascendido socialmente, continuariam contudo insípidas. Nessa leitura, o verso dantesco expressaria os preconceitos da antiga elite brasileira, representada no romance pelo seu pseudoautor, o conselheiro europeizado Aires, o diplomata gentleman, que escreve o seu Memorial de modo preconceituoso em relação aos novos ricos, os negociantes vulgares enriquecidos no período instável economicamente do Brasil da Belle Époque, tais como Santos e Nóbrega.

Silva (2015) chama a atenção para o fato de que, no contexto d'A divina comédia, o verso se refere sobretudo aos inimigos políticos do diplomata Dante; estes seriam as almas desventuradas, "malnascidas", predestinadas desde o nascimento a queimar no inferno. De fato, ao escrever sua obra, o poeta florentino acorrentou diversos inimigos aos círculos infernais, revelando toda a sua fúria vingativa, tal como observa Otto Maria Carpeaux (2010, p. 11) na introdução à obra dantesca: "em sua ira indignada [...] havia algo de fúria vingativa [...] o poeta parece ter sentido uma simpatia secreta com os diabos que castigavam no inferno seus inimigos". Sublinha Silva que, se lá penavam os inimigos políticos de Dante, cá penavam os inimigos de Aires:

Portanto, os representantes, tal como Santos, desta nova elite seriam os inimigos a quem o diplomata Aires desprezaria [...]. Seriam as animas 
mal natas da dantesca epígrafe, pessoas predestinadas desde o nascimento em berço pobre, por mais que depois enriquecessem, à desventura de não serem interessantes, mas antes vulgarmente insípidas. Afinal, se o florentino atribuiu aos seus inimigos políticos pecados capitais dentro do contexto religioso da cristandade medieval, o brasileiro Aires também atribuiria aos seus inimigos, pelo menos um pecado dos mais capitais dentro do contexto mundano da elegante belle époque - e este se atualizaria no pecado moderno da vulgaridade, característica dos insípidos ou pobres de espírito. (SILVA, 2015, p. 330)

Pois, neste trabalho, estamos retomando essas leituras para acrescentar algumas considerações que esperamos terem a sua relevância. Principiemos por notar que, à semelhança do texto dantesco, que dialoga com os discursos prestigiados no seu tempo, tais como a astronomia ptolomaica e a teologia escolástica medieval, o texto machadiano, por sua vez, também está em diálogo com os discursos de prestígio na Belle Époque no Brasil, tais como o positivismo e o determinismo cientificistas, de um lado, e o catolicismo, de outro. Todavia, enquanto o florentino Dante, situado no centro da cultura medieval, construiu um registro literário afirmativo sobre essa cultura, o brasileiro Machado de Assis, situado na periferia da cultura ocidental moderna, construiu, ao contrário, um registro literário crítico em relação aos discursos do seu tempo.

É esse registro crítico que nos propomos a explicitar na referência a Dante mais significativa do romance: o verso que lhe serve de epígrafe. Verso que acena com metafísica e predestinação, porém, deslocado de seu contexto original, anima mal nata adquire no novo contexto um valor materialista e mundano, pois passa a se referir, conforme já foi mencionado, às almas insípidas e vulgares da sociedade do Rio de Janeiro da Belle Époque. De fato, há um deslocamento de sentidos, de sagrado para profano, de metafísico para materialista, com a mudança contextual.

Dico, che quando l'anima mal nata comparece em $A$ divina comédia como uma alusão à doutrina da predestinação divina que afirmava já estar decidido, antes mesmo do nascimento, a salvação ou não de uma alma. Ao comparecer em Esaú e Jacó, no contexto brasileiro do positivismo, o verso, que lá dialogava com uma doutrina religiosa, cá passa a dialogar não somente com essa doutrina, mas também com os determinismos cientificistas que então o Brasil e a sua literatura importavam da Europa.

De fato, é preciso considerar que, publicado em 1904, Esaú e Jacó é contemporâneo da estética naturalista que se prolongou nas letras brasileiras 
até os primeiros anos do século XX. Romances de tese como $O$ cortiço, de 1890, que tentavam demonstrar o determinismo do meio sobre o homem, ainda constituíam uma realidade da literatura no Brasil. Nesse contexto, o fato de Machado de Assis, crítico do Naturalismo, publicar um romance com a epígrafe Dico, che quando l'anima mal nata..., povoado por almas "malnascidas" em berço pobre, cuja insipidez e vulgaridade persistiria, por mais que essas almas ascendessem socialmente, nos motiva a sugerir o diálogo crítico machadiano com a tese cientificista, defendida pela estética naturalista de que o meio determina o homem.

Por outro lado, concordamos com Silva (2015) quando ela afirma que Machado de Assis, ao colocar esta epígrafe em um livro cuja autoria entrega ao diplomata europeizado Aires, está explicitando os preconceitos sociais da elite brasileira da Belle Époque. Trata-se, na verdade, como diria o crítico Roberto Schwarz (1990, p. 78) sobre os narradores machadianos, de "um livro escrito contra o seu pseudoautor". Contudo, estamos acrescentando aqui outra crítica possível, além dessa, ou seja, a crítica de Machado de Assis aos discursos prestigiados por essa elite: de um lado, o positivismo e o determinismo cientificistas, de outro, a religião católica.

Lembremos que, mesmo com a importação do positivismo europeu, o prestígio do catolicismo persistia no Brasil da Belle Époque. Os dois discursos, oriundos de campos contraditórios, ciência e religião, disputavam a estima da elite brasileira, e encontraram em Machado de Assis um crítico contumaz ao longo de toda a sua obra. Pois, ao colocar em Esaú e Jacó o verso dantesco - que já dialogava na versão original com a religião, e que passa a dialogar, nessa versão moderna, também com o cientificismo -, Machado realça as semelhanças guardadas pelos dois discursos. De fato, supostos a princípio como muito diferentes, a predestinação religiosa e o determinismo moderno têm as suas similitudes reveladas na epígrafe: Dico, che quando l'anima mal nata..., o que nos motiva a sugerir que Machado de Assis, ao citar Dante nesse romance, criticamente nivela ciência e religião.

Em suma, o verso dantesco em Esaú e Jacó admite, portanto, ser interpretado como parte integrante da crítica machadiana aos discursos de prestígio no Brasil da Belle Époque, incluindo o próprio discurso naturalista, defensor do positivismo e do determinismo cientificistas, discurso que ainda estava em moda na literatura brasileira do tempo e a respeito do qual Machado de Assis escreveu diversas críticas. 


\section{Considerações finais}

Esperamos que este trabalho tenha, de fato, contribuído para o estudo das referências machadianas à obra $A$ divina comédia, de Dante Alighieri. Revisitamos aqui os poucos críticos que se ocuparam do tema e acrescentamos aos seus estudos algumas considerações que esperamos terem a sua relevância, sobretudo no que diz respeito ao verso dantesco citado em Esaú e Jacó: Dico, che quando l'anima mal nata.

\section{Referências}

ALIGHIERI, Dante. A divina comédia. Edição bilíngue. Trad. Italo Eugenio Mauro. Prefácio de Otto Maria Carpeaux. São Paulo: Editora 34, 2010. 3 v. . La vita nuova di Dante Alighieri. Firenze: Bemporad, 1932.

ANDRADE, Mário de. Machado de Assis. In: —_. Aspectos da literatura brasileira. 5. ed. São Paulo: Livraria Martins Editora, 1974 [1939]. p. 97-102.

ASSIS, Machado de. Obra completa. 3. ed. São Paulo: Nova Aguilar, 2015a. v. 1. . Obra completa. 3. ed. São Paulo: Nova Aguilar, 2015b. v. 2. . Obra completa. 3. ed. São Paulo: Nova Aguilar, 2015c. v. 3. Obra completa. 3. ed. São Paulo: Nova Aguilar, 2015d.v. 4.

BIZARRI, Edoardo. Machado de Assis e a Itália. Caderno do Instituto Cultural ÍtaloBrasileiro, São Paulo, n. 1, 1961. . Machado de Assis e Dante. Caderno do Instituto Cultural Ítalo-Brasileiro, "O meu Dante", São Paulo, n. 5, p. 133-144, 1965.

CARPEAUX, Otto Maria. Sobre a divina comédia. In: ALIGHIERI, Dante. A divina comédia. Edição bilíngue. Trad. Italo Eugenio Mauro. São Paulo: Editora 34, 2010. v. 1, p. 7-18.

CESCHIN, Osvaldo Humberto Leonardi. Uma página dantesca de Machado de Assis. Revista do Instituto Italiano de Cultura, São Paulo, v. 8, p. 104-109, 1999.

FLORES, Diego. Diálogos em tradução: Augusto de Campos e Machado de Assis. Caderno de Tradução, Florianópolis, v. 37, n. 13, p. 117-138, 2017. Disponível em: <www.periodicos.ufsc.br>. Acesso em: 20 mai. 2018.

GOMES, Eugênio. As influências inglesas em Machado de Assis. Bahia: [s.e.]: 1939. . O testamento estético de Machado de Assis. In: ASSIS, Machado de. Obra completa. 3. ed. São Paulo: Nova Aguilar, 2015. v. 1, p. 85-106.

JOBIM, José Luís. (Org.). A biblioteca de Machado de Assis. Rio de Janeiro: ABL; Topbooks, 2001.

MAGALHÃES Jr., Raimundo. Vida e obra de Machado de Assis. Rio de Janeiro: Civilização Brasileira, 1981. v. 1. 
MASSA, Jean-Michel. La Bibliothèque de Machado de Assis. Revista do Livro, Rio de Janeiro, Instituto Nacional do Livro, v. 6, n. 21-22, p. 195-238, 1961. . Presença de Dante na obra de Machado de Assis. Trad. E. V. de Moraes; M. A. C. Capello. Machado de Assis em linha, São Paulo, v. 8, n. 16, p. 138-148, dez. 2015. Disponível em: < http://machadodeassis.fflch.usp.br>. Acesso em: 15 out. 2018.

. Machado de Assis tradutor. Trad. O. S. Ferraz. Belo Horizonte: Crisálidas, 2008.

MERQUIOR, José Guilherme. De Anchieta a Euclides: breve história da literatura brasileira. Rio de Janeiro: José Olympio, 1977.

MORAES, Eugênio Vinci. A tijuca e o pântano: "A Divina Comédia" na obra de Machado de Assis entre 1870 e 1881. 2007. 179 f. Tese (Doutorado em Literatura Brasileira) - Faculdade de Filosofia, Letras e Ciências Humanas, Universidade de São Paulo, São Paulo, 2007. Disponível em: <www.teses.usp.br/teses/disponíveis>. Acesso em: 11 out. 2018.

PASSOS, Gilberto Pinheiro. A poética do legado: presença francesa em Memórias póstumas de Brás Cubas. São Paulo: Annablume, 1996.

SCHWARZ, Roberto. Machado de Assis: um mestre na periferia do capitalismo. São Paulo: Duas Cidades, 1990.

SILVA, Teresinha V. Zimbrão da. Machado de Assis: Dico, che quando l'anima mal nata. Revista Estação Literária, Londrina, v. 13, p. 324-334, jan. 2015. Disponível em: <www.uel.br/revistas/uel/index.php/estacaoliteraria>. Acesso em: 10 out. 2018.

TERESINHA V. ZIMBRÃO DA SILVA é doutora em Literatura pela University of Newcastle Upon Tyne (1994), com pós-doutorado em Literatura pela PUC-Rio (2007). É Professora Titular da Graduação e da Pós-Graduação em Letras da Universidade Federal de Juiz de Fora. Sobre Machado de Assis publicou os artigos: "Espiritualidade em Machado de Assis" (Graphos, 2017), "O sermão do diabo: uma irreverência machadiana" (Verbo de Minas, 2016), "Machado de Assis: Dico, che quando l'anima mal nata" (Estação Literária, 2014), e "Machado de Assis e o mulato de 'alma grega'" (Machado de Assis em linha, 2014). E-mail: teresinha.zimbrao@gmail.com

IZABELLA MADDALENO é mestre em Letras pela Universidade Federal de Juiz de Fora com a dissertação Um diabo narrado pelas tintas machadianas. Atualmente, é doutoranda em Letras também pela UFJF, sob orientação da professora doutora Teresinha Vânia Zimbrão da Silva, atuando ainda como professora substituta de italiano na mesma instituição em que cursa o doutorado. E-mail: izabellaletras@gmail.com

Recebido: 14.11.2018

Aprovado: 25.02.2019 